Structural Safety, Volume 76, January 2019, Pages 40-50.

\title{
Quantifying monitoring requirements for predicting creep deformations through Bayesian updating methods
}

\author{
Helder Sousa $^{(1)}$, Luís Oliveira Santos ${ }^{(2)}$, Marios Chryssanthopoulos ${ }^{(1)}$ \\ (1) University of Surrey, Guildford, Surrey GU2 7XH United Kingdom \\ (2) Laboratório Nacional de Engenharia Civil, Lisbon, Portugal
}

\begin{abstract}
Although the majority of creep models are comprehensive and up-to-date, there is a lack of consensus in their utilisation due to substantial scatter in their predictions, even when comparisons are made under well-controlled conditions. On one hand, creep entails complex phenomena that depend on several factors and, on the other hand, these models are typically utilised on a deterministic basis without fully incorporating information related to random input variability.
\end{abstract}

In this paper, a methodology is proposed, based on Bayesian updating methods, for creep deformation prediction by combining prior model distributions obtained through Monte Carlo simulation with in-situ measurements obtained from concrete specimens. Both single point-in-time and sequential updating approaches are formulated and contrasted in the context of site data collected over a period of about six years. For the specific structure examined, the sequential updating method offers advantages in terms of the estimated variability of future predictions. The proposed methodology is suitable for quantifying the value of monitoring information, as demonstrated by considering the change in prediction variability against the length of observation period.

Keywords: Creep, Concrete bridges, Bayesian updating, Value of information 


\section{Introduction}

Over the past century, European countries have developed mature and extensive transport infrastructure networks, in which bridges play a vital role. Focussing on pre-stressed concrete bridges, the most important aspect in life-cycle design is the performance-time profile of the Serviceability Limit State (SLS), usually related to cracking, excessive deflection and vibration [1], which in turn may influence other limit states. Particularly for segmental bridges, the risk of a significant increase in long-term deflections has been shown to exist [2]. For example, the collapse of the Koror-Babeldaob Bridge, Palau, was recently re-assessed and attributed to excessive long-term deflections [3]. These appeared and grew non-linearly some years after construction, as result of material interactions, i.e. creep, shrinkage (concrete) and relaxation (prestressing steel). Indeed, the time-dependent creep and shrinkage structural effects in segmental bridges are more critical than in other types of concrete bridges. Creep strains are higher when concrete is loaded at a younger age and, thus, interactions with loss of prestressing are stronger, leading to increased displacements [4]. In this context, understanding the development of creep and shrinkage deformation-time profiles is crucial.

Focussing on the creep of concrete, although most of the models are relatively recent and comprehensive, there is a lack of consensus in their utilisation due to substantial scatter in their predictions. A major obstacle to progress has been the lack of multi-decade measurements and the dependence of creep on complex interactions between material composition, element shape and size, as well as curing and environmental conditions over time. The majority of available measurement datasets do not possess a sufficient time range to provide information on the functional form of time profiles and to describe the trends associated with loading age, element thickness and environmental humidity [5]. Indeed, while lifetimes in excess of 100 years are nowadays required in designing bridges, only $5 \%$ of laboratory tests in the RILEM and NU-ITI databases have a duration over 6 years, and only $3 \%$ extend over 12 years [6]. Moreover, existing multi-decade creep tests contain 
only limited information regarding concrete composition and environmental effects [5], whereas the compilation of databases has revealed various shortcomings in testing, recording and reporting procedures. This has led to recommendations for more comprehensive testing protocols [5]. In this regard, substantial progress could be achieved through the generation of new multi-decade data from bridges and other structures, provided that their documentation is appropriate for inverse analysis [6].

The available uniaxial stress creep models have usually been developed in a deterministic framework, despite the fact that the underlying phenomena are influenced by several factors with significant randomness, even when specimens are made under relatively tight conditions. Analysis of residuals (i.e. difference between predictions and measurements) is then typically employed a posteriori to assess the accuracy of models $[7,8]$. Likewise, sensitivity analysis may be conducted to investigate the relative importance of the different input parameters in creep and shrinkage models $[9,10]$. Nonetheless, these studies are commonly underpinned by short-term measurements and do not consider uncertainty modelling in an appropriate context.

The utilisation of a Bayesian approach in creep prediction dates back over thirty years when Bažant and his associates introduced it, through a simplified (linearized) compliance model, to a number of different cases and presented in detail potential benefits and limitations arising from this approach $[11,12]$. Many important aspects were discussed, including the effect of correlation arising from the use of successive creep measurements and the interplay between prior models and the statistics of the likelihood function. Moreover, a Bayesian approach has been implemented at the structural level, through which improvements (i.e. reduction on the uncertainty) in estimating long-term deflections and internal forces in a segmental box girder bridge have been demonstrated [13]. However, the limited in situ data available at the time, together with computational constraints, introduced limitations to the analysis and the generated results. 
In this context, this paper re-visits the Bayesian approach applied to the problem of creep deformation prediction by combining prior model distributions obtained through Monte Carlo simulation with in-situ measurements obtained from concrete creep specimens placed in a field environment over a period of several years. In particular, it focuses on aspects of the Bayesian methodology that need to be tailored to the problem in hand, depending on availability and robustness characteristics of in-situ data. Both single point-in-time and sequential updating approaches are developed and demonstrated through a case study that utilises such data from a prestressed concrete bridge collected over a period of more than six years. The objective is to understand the limitations of having to rely on small samples and incomplete information on actual conditions, leading to a range of predictive distributions for creep compliance. The question of how long the in-situ measurements should be extended in time is addressed, in the light of monitoring considerations, e.g. feasibility/robustness of data acquisition and costs, within a value of information context represented by the reduction in prediction variability vis-à-vis the length of the observation period.

\section{Creep deformations}

\section{Analytical models}

Codified models for concrete creep are semi-empirical and are calibrated/validated using laboratory experiments. Supported by the RILEM database, researchers $[7,14]$ have investigated several of those models with the objective of drawing conclusions through detailed comparisons. Generally, it has been concluded that the B3 and GL2000 models exhibit a better performance overall. Recently, in response to advances in concrete technology, the B4 model has been adopted by RILEM [15], which represents an improvement over B3, though its general mathematical form has remained the same, except for the part dealing with autogenous shrinkage. Considering the age and construction characteristics of the bridge analysed as a case study in this work, the B3 model is selected for further use, alongside the GL2000 model and the current Eurocode (EC2) model, the latter being of 
particular interest to practitioners in Europe. A detailed description of the selected models can be found elsewhere $[1,16,17]$ with Table 1 summarizing their input parameters. The number of input parameters ranges from 7 (EC2) to 11 (B3) with evident differences. In applying the models to an existing structure, some of the input parameters might be reasonably taken to be deterministic, whereas others should be treated as random variables. The identification of the latter is important since it affects considerably the dispersion of the predictions for creep over time. In this paper, bearing in mind the way in which these models will be utilised as prior predictions to be combined with site specific measurements from a single structure, the following are singled out as random variables: (i) mean compressive strength of concrete at 28 days $\left(f_{\mathrm{cm}, 28 \mathrm{~d}}\right)$, (ii) Young's modulus of concrete at 28 days $\left(\mathrm{E}_{\mathrm{cm}, 28 \mathrm{~d}}\right)$ (iii) relative humidity (RH), (iv) cement content $(\mathrm{C})$, (v) water-cement ratio $(\mathrm{W} / \mathrm{C})$ and (vi) aggregate-cement ratio $(\mathrm{A} / \mathrm{C})$. As can be seen, these are related to mix composition, mechanical properties and prevailing environmental conditions. In contrast, it is assumed that, for a specific structure, the type of cement used, key points in time related to curing and loading and certain geometric parameters can be taken as deterministic.

Table 1: List of input parameters for creep models.

\begin{tabular}{lcccc}
\hline \multicolumn{1}{c}{ Input parameter } & & B3 & EC2 & GL2000 \\
\hline Mean compressive strength, 28d & $f_{c m, 28 d}$ & $\checkmark$ & $\checkmark$ & $\checkmark$ \\
Young's modulus, 28d & $E_{c m, 28}$ & $\checkmark$ & $\checkmark$ & $\checkmark$ \\
Young's modulus at loading & $\left.E_{c} t_{0}\right)$ & & $\checkmark$ & $\checkmark$ \\
Strength development & $s$ & & $\checkmark$ & $\checkmark$ \\
Relative Humidity & $R H$ & $\checkmark$ & $\checkmark$ & \\
Beginning of drying & $t_{c}$ & $\checkmark$ & & $\checkmark$ \\
Age of concrete at loading & $t_{0}$ & $\checkmark$ & $\checkmark$ & $\checkmark$ \\
Volume-Surface ratio & $V / S$ & $\checkmark$ & & $\checkmark$ \\
Notional size & $h_{0}$ & & $\checkmark$ & \\
Shape of cross-section & - & $\checkmark$ & & \\
Type of cement & - & & & $\checkmark$ \\
Cement content & $C$ & $\checkmark$ & & \\
Water content & $W$ & $\checkmark$ & & \\
Water-Cement ratio & $W / C$ & $\checkmark$ & & \\
Aggregate-Cement ratio & $A / C$ & $\checkmark$ & & \\
\hline
\end{tabular}




\section{Field measurements}

The analysis presented herein is supported by a well-documented testbed offering extensive field data - the São João Bridge, for which a set of creep measurements at specimen level are available with a comprehensive characterization of the employed concrete and good understanding of the prevailing environment. A monitoring system was installed during the bridge construction [18], which has allowed the collection of measurements from an early age, i.e. concrete pouring. Among several monitored parameters, special attention was given to the characterization of the employed concrete and, in turn, of creep and shrinkage. Specifically, fifteen specimens were cast with two long unsealed faces and different sections: (i) six with dimensions $30 \times 30 \times 60 \mathrm{~cm}$, (ii) six with dimensions $30 \times 35 \times 60 \mathrm{~cm}$ and (iii) three with dimensions $30 \times 50 \times 60 \mathrm{~cm}$. An equal number of specimens with the same dimensions were used for the characterization of creep. All these samples were kept in an experimental stave, placed next to the bridge, on the south riverbank. More specifically, a vibrating wire strain gauge was placed inside each prism to measure the concrete strain. Whereas the shrinkage specimens were not loaded and subjected only to the environmental conditions, the creep specimens, of interest herein, were subjected to a constant uniaxial load imposed by a hydraulic-based jack system that maintains a constant pressure, which in this case was set to $5 \mathrm{MPa}$ [19]. This value is representative of the magnitude of the operational (serviceability) stress level in the concrete of the bridge [18], which is also well within the limit of $0.45 \cdot \mathrm{f}_{\mathrm{ck}}$ suggested in EC2 [1] to ensure that the material behaviour lies within the linear creep domain.

\section{Uncertainty modelling}

The use of current creep models results in considerable prediction scatter stemming from several sources of uncertainty both aleatory and epistemic. Table 2 presents probabilistic models for the set of input random variables based on in-situ information (i.e. utilising data available from the São João bridge) related to the employed concrete and surrounding environmental conditions [18]. In 
particular, the results from 105 cube tests, pertaining to the same batches as those used in producing the creep specimens, were considered for $f_{c m, 28 d}$, whereas $E_{c m, 28 d}$ was treated as a derived random variable through the EC2 expression that links $E_{c m}$ to $f_{c m}$. Model uncertainty, $X_{m}$, is also taken into account with reference values taken from [7], in which a large dataset of experimental results from creep specimens is analysed in order to quantify the model uncertainty statistics associated with different creep prediction models. In the case of the concrete mix parameters, i.e. $C, W / C$ and $A / C$, and in the absence of statistical information from the actual concrete batches delivered for bridge construction, the standard deviation was set based on information available in the literature for a concrete grade similar to that employed in the bridge. In accordance with preceding studies $[5,10]$, the statistical dependence between random variables is taken into account through the correlation matrix presented in Table 3.

Regarding the deterministic quantities, the following points are relevant: (i) the strength development parameter, s, is set equal to 0.24 , (ii) the curing conditions is considered moist, (iii) the concrete is exposed to drying at $t_{s}=1$ day and (iv) loaded at $t_{0}=7$ days, (v) the Volume-Surface ratio, $V / S$, is $150 \mathrm{~mm}$, (vi) the notional size, $h_{0}$, is $300 \mathrm{~mm}$, (vii) the shape of the cross section is taken as an infinite square prism and (viii) the type of cement is CEM I $42.5 \mathrm{R}$.

Table 2: Description of random variables.

\begin{tabular}{|c|c|c|c|c|c|c|}
\hline \# & $\begin{array}{c}\text { Variable } \\
\qquad X_{n}\end{array}$ & $\begin{array}{l}\text { Mean } \\
\qquad \bar{X}\end{array}$ & $\begin{array}{c}\text { Standard } \\
\text { deviation } \\
{ }_{S} X_{n}\end{array}$ & $\begin{array}{c}\text { Distribution } \\
\qquad f\left(\bar{X}_{n}, s^{X_{n}}\right)\end{array}$ & Units & Source \\
\hline 1 & $f_{c m, 28 d}$ & 51.1 & 3.58 & Log-normal & $\mathrm{MPa}$ & [21] \\
\hline 2 & $E_{c m, 28 d}$ & 34.7 & 2.43 & Log-normal & $\mathrm{GPa}$ & [21] \\
\hline 3 & $R H$ & 70.0 & 3.50 & Extreme Value & $\%$ & [22] \\
\hline 4 & $C$ & 474 & 47.4 & Log-normal & $\mathrm{Kg} / \mathrm{m}^{3}$ & {$[10,11]$} \\
\hline 5 & $W / C$ & 0.39 & 0.04 & Log-normal & - & {$[10,11]$} \\
\hline 6 & $A / C$ & 3.60 & 0.36 & Log-normal & - & {$[10,11]$} \\
\hline 7 & $X_{m}(\mathrm{~B} 3)$ & 0.93 & 0.33 & Log-Normal & - & [7] \\
\hline 8 & $X_{m}(\mathrm{EC} 2)$ & 0.89 & 0.28 & Log-Normal & - & [7] \\
\hline 9 & $X_{m}(G L 2000)$ & 0.92 & 0.31 & Log-Normal & - & [7] \\
\hline
\end{tabular}


Table 3: Correlation matrix between random variables.

\begin{tabular}{ccccccc}
\hline & $f_{c m, 28 d}$ & $E_{c, 28 d}$ & $R H$ & $C$ & $W / C$ & $A / C$ \\
\hline$f_{c m, 28 d}$ & 1.0 & 0.6 & 0.0 & 0.5 & -0.6 & -0.4 \\
$E_{c, 28 d}$ & & 1.0 & 0.0 & 0.3 & -0.3 & -0.1 \\
$R H$ & & 1.0 & 0.0 & 0.0 & 0.0 \\
$C$ & & & & 1.0 & -0.8 & -0.9 \\
$W / C$ & & & & & 1.0 & 0.8 \\
$A / C$ & & & & & & 1.0 \\
\hline
\end{tabular}

\section{Bayesian Updating Methodology}

\section{Single point updating}

According to Bayes' theorem, updated information is achieved about a parameter $\theta$ based on initial state of knowledge about that same parameter and the knowledge gained from a set of observations $y$.

For continuous variables, Bayes' Theorem is formulated in terms of probability density functions (PDF) as follows:

$$
\pi(\theta \mid y)=\frac{f(y \mid \theta) \pi(\theta)}{\int f(y \mid \theta) \pi(\theta) d \theta} \propto f(y \mid \theta) \pi(\theta) \#(1)
$$

Where $f(y \mid \theta)$ is the conditional PDF of $y$ given $\theta$ (sampling distribution or likelihood function), $\pi(\theta)$ is the PDF of $\theta$ (prior distribution), $\pi(\theta y)$ is the conditional PDF of $\theta$ given y (posterior distribution). The denominator of Eq. 1 is a normalizing constant, assuring that the area under the posterior distribution is equal to unity. It is important to realize that the prior must not be constructed with information derived from the observations, which implies that the prior should be independent of the likelihood and therefore, the observations do not influence the choice of the prior. 


\section{Sequential updating}

If the continuous random variable $y$ is stochastic, i.e. it may be generated sequentially in time $y_{1}, \ldots$, $y_{i}, \ldots$, and it is intended to update inference on the parameter $\theta$, this can be set by replacing the usual expression for a Bayesian updating scheme (Eq. 1) with an analogous expression

$$
\pi_{i+1}(\theta \mid y) \propto f\left(y_{i+1} \mid \theta\right) \pi_{i}(\theta), i=1,2, \ldots, n \#(2)
$$

where it can be claimed that just before the next time step, i.e. $i+1$, the knowledge of $\theta$ is summarized in the distribution $\pi_{i}(\theta)$. Consequently, the latter is used as a prior distribution for the next time step $i+1$. In this dynamic perspective, it is evident that characterization of $\pi_{i}$ is only required at time step $i$, and no earlier information needs to be retrieved. In other words, the latest $\pi_{i}$ contains all knowledge relevant for updating when confronted with new information $f\left(y_{i+1} \mid \theta\right)$.

\section{Implementation for creep prediction}

In the context of updating the creep distribution up to a point-in-time when observations are available and, furthermore, predicting the same distribution for a subsequent point-in-time, a Bayesian approach starting from Eq. 1 and Eq. 2 was implemented allowing utilization of in-situ specimen data. Thus, the following formulations were developed and used within a stepwise approach, which is detailed below:

$$
\begin{gathered}
\pi\left[J\left(t_{f}, t_{0}\right) \mid \tilde{J}\left(t_{i}, t_{0}\right)\right] \propto f\left[\tilde{J}\left(t_{f}, t_{0}\right) \mid J\left(t_{i}, t_{0}\right)\right] \cdot \pi\left[J\left(t_{i}, t_{0}\right)\right] \#(3) \\
\pi_{i+1}\left[J\left(t_{f}, t_{0}\right) \mid \tilde{J}\left(t_{i}, t_{0}\right)\right] \propto f\left[\tilde{J}\left(t_{i+1}, t_{0}\right) \mid J\left(t_{f}, t_{0}\right)\right] \cdot \pi_{i}\left[J\left(t_{i}, t_{0}\right)\right], i=1,2, \ldots, n \#(4)
\end{gathered}
$$


Where (i) $J\left(t_{f}, t_{0}\right)$ is the compliance at the final time, $t_{f}$, when loading starts at time $t_{0}$, (ii) $\tilde{J}\left(t_{i}, t_{0}\right)$ is the compliance (obtained from the test specimens) at any given date, $t_{i}$, when loading starts at time $t_{0}$ and (iii) $i$ is an index related to the sampling frequency of the experimental values. Based on this formulation, the proposed methodology comprises the following five main steps (see Figure 1):

Step 1 : Characterization of the predicted creep compliance - Generation of a set of time-series for a selected creep model based on a Monte Carlo simulation and the characterization of the random variables (Table 2). Quantification of the prior distribution $\pi\left[J\left(t, t_{0}\right)\right]$ and the mean, $\mu_{J}\left(t, t_{0}\right)$, and standard deviation, $\sigma_{J}\left(t, t_{0}\right)$, over time.

\section{Step 2 : Characterization of the measured creep compliance - Selection of a set of creep} measurements over time. Quantification of the mean, $\mu_{\tilde{J}}\left(t, t_{0}\right)$, and standard deviation, $\sigma_{\tilde{J}}\left(t, t_{0}\right)$, over time.

Step 3: Characterization of the likelihood distribution - Generation of the likelihood distribution for $\mathrm{t}=\mathrm{t}_{\mathrm{i}}, f\left[\tilde{J}\left(t_{i}, t_{0}\right) \mid J\left(t_{i}, t_{0}\right)\right]$, based on the mean and standard deviation calculated in Step 2.

Step 4: Characterization of the posterior distribution - Quantification of the posterior distribution for $\mathrm{t}=\mathrm{t}_{\mathrm{i}}$, based either on the single point updating method, $\pi\left[J\left(t_{i}, t_{0}\right) \mid \tilde{J}\left(t_{i}, t_{0}\right)\right]$, or the sequential updating $\pi_{i+1}\left[J\left(t_{i}, t_{0}\right) \mid \tilde{J}\left(t_{i}, t_{0}\right)\right]$ (Eq. 3 or Eq. 4, respectively).

Step 5: Characterization of the posterior distribution for the final date, $t_{f}-$ Quantification of the posterior distribution for the final date, $t_{f}, \pi\left[J\left(\mathrm{t}_{\mathrm{f}}, \mathrm{t}_{0}\right) \mid \tilde{\mathrm{J}}\left(\mathrm{t}_{\mathrm{i}}, \mathrm{t}_{0}\right)\right]$, based on the extrapolation of the posterior distribution calculated in Step 4. 


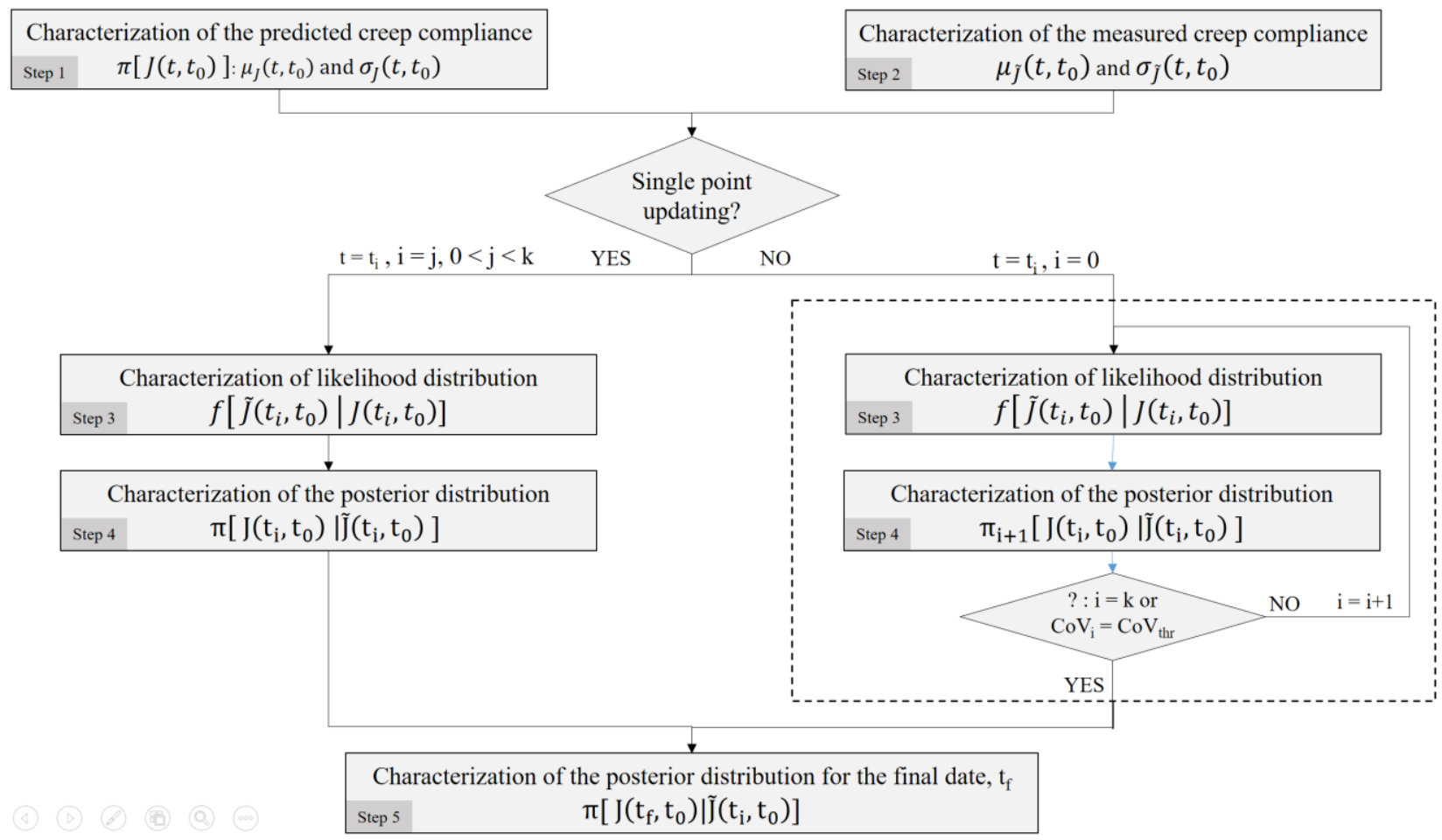

Figure 1: Algorithm for the characterization of the final creep compliance.

It is worth noting that in the case of sequential updating, the algorithm can be utilized so as to estimate the observation period that is required to obtain a posterior creep distribution with a $\mathrm{CoV}$ below a threshold value (as shown in the last decision box on the right-hand side of Figure 1). This is useful in the context of pre-posterior analysis, where it could be desirable to establish, in quantitative terms, the required experimental observation period of creep deformations at the specimen level.

\section{Case study: S. João Bridge, Portugal}

São João Bridge is a railway bridge crossing the River Douro, in Porto, Portugal. Designed by Edgar Cardoso, it has been open to traffic since 1991. It is a prestressed concrete bridge, with a total length of $1028 \mathrm{~m}$, including a main span of 250 metres, two $125 \mathrm{~m}$ side spans and approaching viaducts from either side of the riverbanks (Figure 2). The twin-cell box main girder, built by the cantilever method, has a trapezoidal cross-section with a variable height of $12 \mathrm{~m}$ near the main piers decreasing 
to $7 \mathrm{~m}$ at mid-span. The bottom slab thickness decreases from $2.45 \mathrm{~m}$ near the main piers to $0.30 \mathrm{~m}$ at mid-span. The main piers, $50 \mathrm{~m}$ high, have a circular cross section becoming rectangular at their top [18].

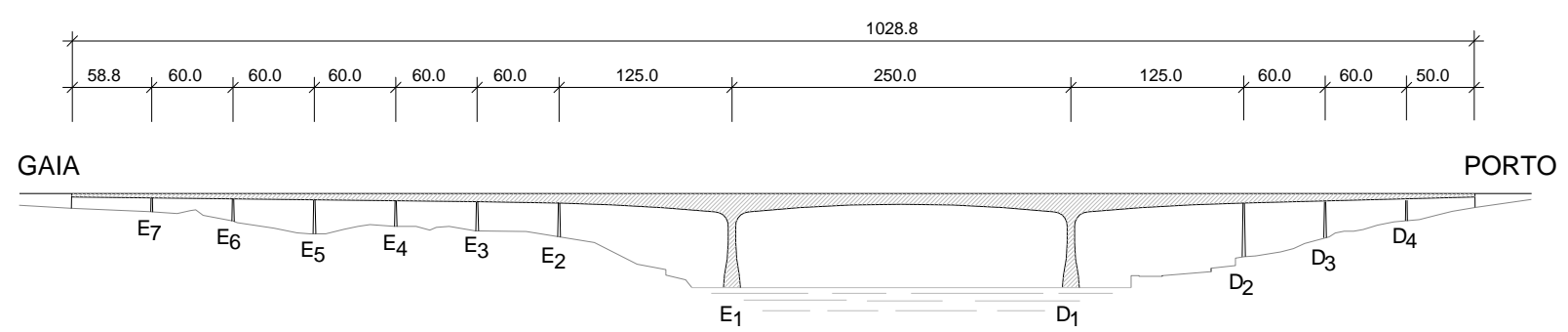

Figure 2: São João Bridge.

Data collected from six creep specimens with a notional size of $300 \mathrm{~mm}$ associated with the concrete used in the S. João Bridge are used to demonstrate the proposed updating methodology. As mentioned above, three models were used to obtain prior predictions, namely B3, EC2 and GL2000. It is generally accepted that assessment of creep-sensitive bridges, such as the S. João Bridge, can be enhanced by utilising creep information at specimen level, since it can be used as input in numerical models (typically FE) that investigate behaviour at structural level [19, 23]. Moreover, this can be performed on the basis of some additional site knowledge regarding the creep compliance function at the specimen level. This function represents the evolution of creep deformations over time per unit of stress, which is then widely accepted as the most appropriate input at the structural level [24, 25]. The present study focuses on the analysis at specimen level in order to demonstrate the potential of Bayesian updating methods in interpreting creep test results and how they might be integrated with creep prediction models. In addition, different scenarios were explored, in order to enrich the discussion by considering options with regard to the collection of site data and the asset management objectives: 
- Different collection frequencies are assumed for collecting in-situ measurements, namely: (i) every month, (ii) every 4 months and (iii) every 12 months;

- An estimation of the posterior distribution for creep compliance is made for different 'final' dates, $t_{f}$, since the construction of the bridge, namely, (i) $t_{f}=2297$ days ( $\cong 6.3$ years) and (ii) $\mathrm{t}_{\mathrm{f}}=5840$ days $(\cong 16$ years $)$.

\section{Characterization of the likelihood function for creep compliance}

Creep compliance is calculated by dividing the measured creep strain by the magnitude of the load applied to each specimen. The results are presented in Figure 3. As can be seen, one of the six specimens deviates from the remaining five (i.e. specimen CF1.1), and this was attributed to the higher modulus of elasticity estimated for this specimen, $E_{c}=33 \mathrm{GPa}$, against an average of $\mathrm{E}_{\mathrm{c}}=29.4 \mathrm{GPa}$ for the remaining five. However, this higher value was the result of the test for this single specimen being carried out at a later date compared to the rest, thus introducing an undesirable inconsistency in estimating compliance values. It was, therefore, decided to characterise the evolution of mean and the standard deviation of the compliance based on the remaining five observations (i.e. specimens CF2.1, CF3.1, CF4.1, CF8.1 and CF9.1). Figure 3 shows the compliance derived from the five creep measurements and their respective mean. It should be mentioned that strain measurements from the different specimens were not collected concurrently. To overcome this, the collected data were normalized by using the spline function available in MATLAB [26]. 


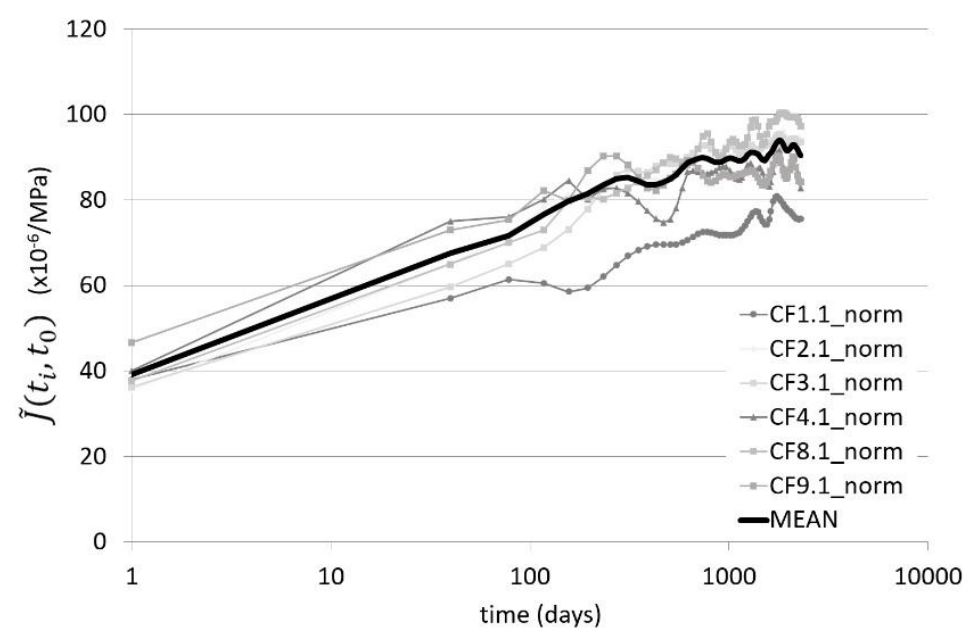

Figure 3: Compliance measurements for the six concrete specimens (mean based on five used in the analysis).

The compliance time profiles presented in Figure 3 are further analysed using regression analysis, as presented in Figure 4. As can be seen, there is strong positive correlation between mean compliance and time $\left(\mathrm{R}^{2} \cong 0.89\right)$, which means that this parameter can be estimated using the regression equation shown therein. In contrast, the correlation of the standard deviation of measured compliance with time is negligible (i.e. $\mathrm{R}^{2}=0.03$ ) and, therefore, it is modelled as a time invariant random variable with mean value of $4.3 \mu \varepsilon / \mathrm{MPa}$ and a standard error, to account for statistical uncertainties, equal to $1.2 \mu \varepsilon / \mathrm{MPa}(\mathrm{CoV}$ of $28 \%)$. No information was found in the literature regarding the time dependency of statistical properties associated with creep compliance. Based on the limited evidence associated with the small number of specimen tests analysed herein, the above estimates are tentatively suggested, though more research in this area would be beneficial. 


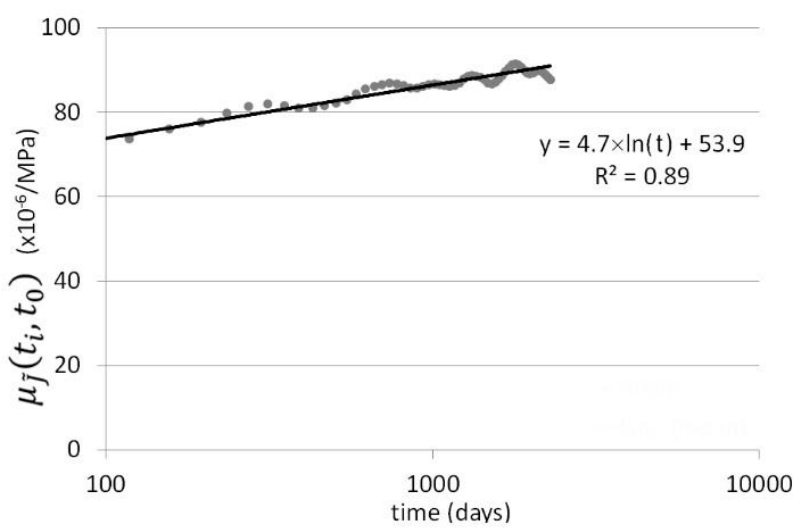

a)

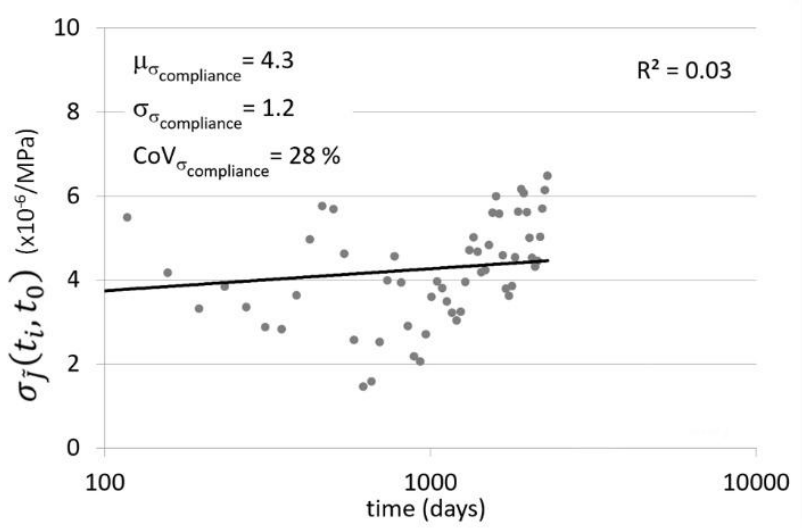

b)

Figure 4: Mean, $\mu_{\tilde{J}}\left(t_{i}, t_{0}\right)$, and standard deviation, $\sigma_{\tilde{J}}\left(t_{i}, t_{0}\right)$, of the measured compliance over time.

These first and second moment estimates are used to characterise the likelihood function to be used in the Bayesian updating process. It is assumed that the measured values of compliance are unbiased and that, therefore, their mean value at any given point in time can be taken as the mean of the likelihood function. Moreover, based on an analysis of the prior distributions of creep compliance (see following section), a log-normal distribution is assumed for the likelihood function at any given point in time, whose parameters can be obtained from the estimated mean and standard deviation of the measurements at the same point in time.

An analysis of residuals was also undertaken. Specifically, the difference between the value of the

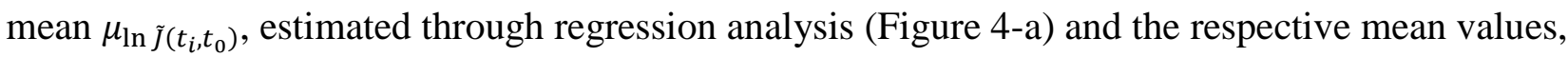
directly obtained from measurements (Figure 3), were calculated for each point in time where measurements are available. Figure 5 shows the CDF of calculated residuals together with a normal fit. Overall, the residuals are satisfactorily approximated by a normal distribution even though a Kolmogorov-Smirnov test was not supportive [27]. Although other probabilistic models could have been trialled, they would not strictly conform to the assumptions inherent in least-square estimation and were, therefore, not considered. 


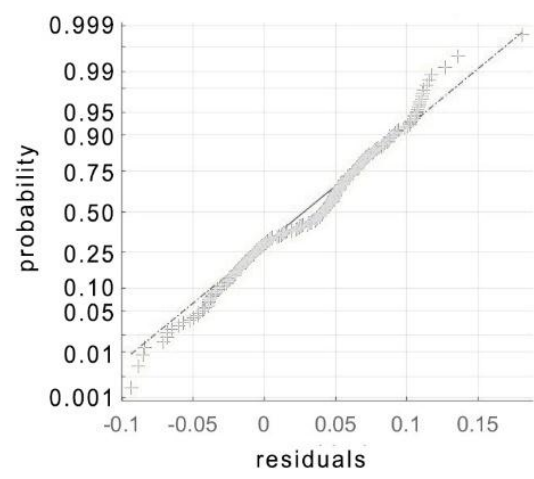

Figure 5: Residual analysis related to $\mu_{\ln \tilde{J}\left(t_{i}, t_{0}\right)}$ - normal probability plot.

\section{Characterization of the prior distribution for creep compliance}

With regard to the characterization of the predicted compliance, a Monte Carlo simulation was performed for each model considered (i.e. B3, EC2, GL2000) using the probabilistic modelling input presented in Tables 2 and 3. Simulation sampling errors were investigated by considering sample sizes up to 12,500 and comparing the $\mathrm{CoV}$ of predicted compliance at a given point-in-time, more precisely for $\mathrm{t}=\mathrm{t}_{\mathrm{f}}=5840$ days $(\cong 10$ years after the last measurement collection and 16 years from construction). Based on the results presented in Figure 6, the sample size for performing the updating scheme shown in Figure 1 was fixed at 5,000. Figure 7 shows the scatter of the predicted creep compliance as a function of time (i.e. step 1 in Figure 1), together with the mean compliance estimated using measurements from the five in situ specimens. There are noticeable differences in these three plots, with GL2000 and B3 producing higher scatter than EC2 throughout the time period considered. This may be attributed to the higher number of input variables considered in the former, especially B3, which leads to a wider prediction range for a particular structure. In this respect, the importance of being able to link these simulated profiles to collected evidence becomes clear. Based on the results shown in Figure 7, Figure 8 shows the histograms for creep compliance obtained for $\mathrm{t}$ $=2297$ days, where the abovementioned effects can be better appreciated. Lognormal distributions provided good fit to these histograms, with their parameters obtained using standard MLE techniques. It is worth mentioning that Model Code 2010 assumes a normal distribution for creep 
compliance based on a computerized database of laboratory test results [23]. However, this hypothesis is not supported by the results obtained herein and all three models produce similar trends insofar as the appropriate distribution type for prior compliance is concerned (Figure 8).

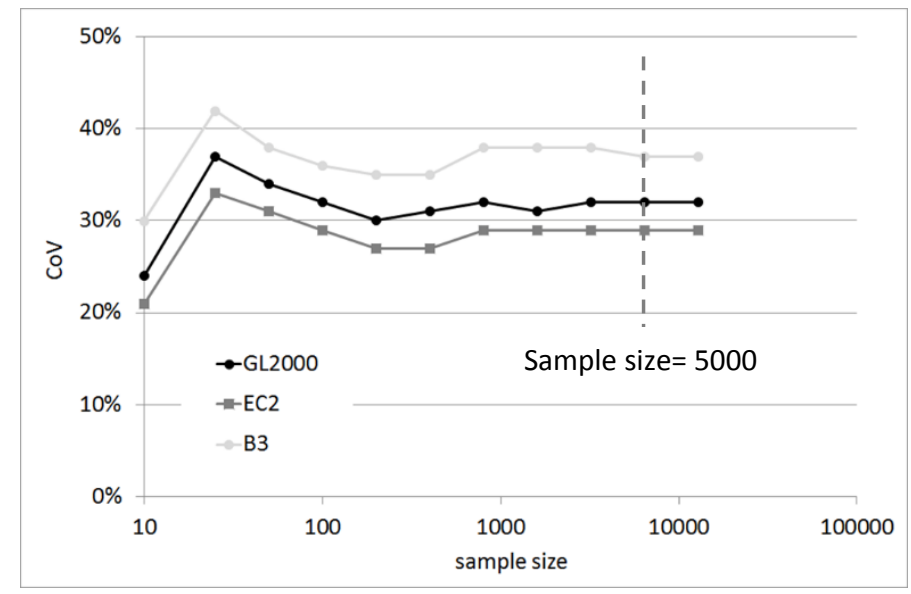

Figure 6: Evolution of the compliance $\mathrm{CoV}$ with the sample size. 


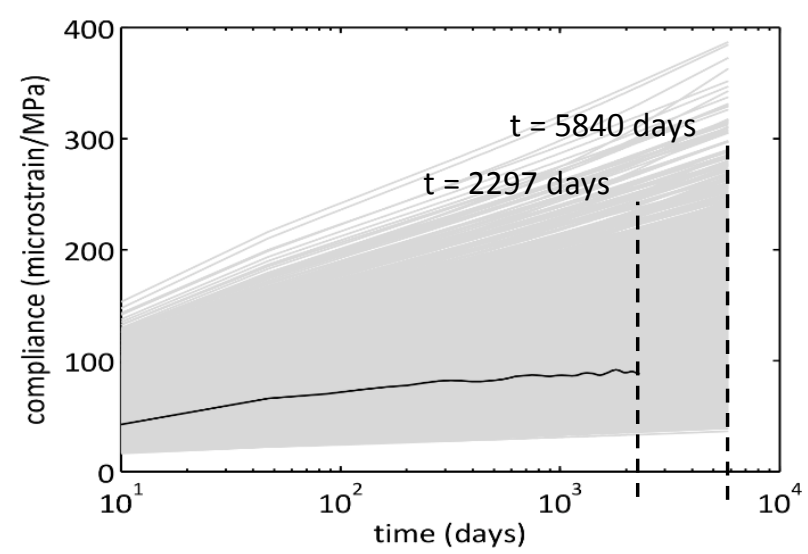

a)

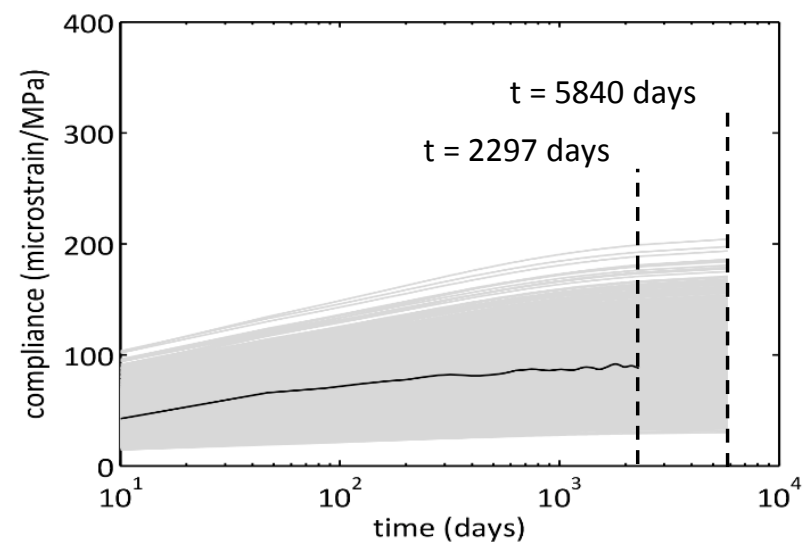

b)

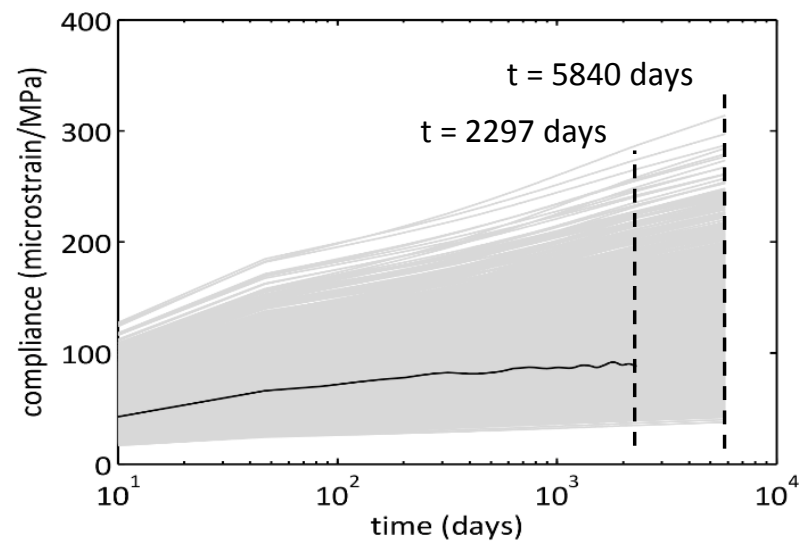

c)

Figure 7: Compliance - measurements' mean, $\mu_{\tilde{J}\left(t, t_{0}\right)}$, vs. model predictions, $J\left(t, t_{0}\right)$ : a) B3, b) EC2, c) GL2000. 


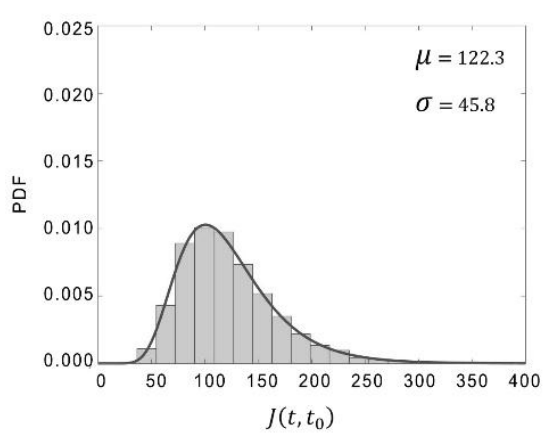

a)

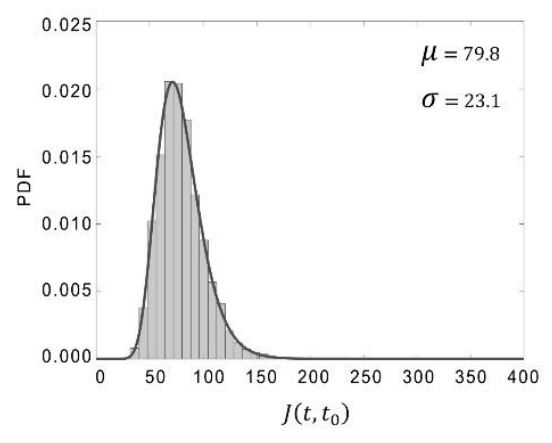

b)

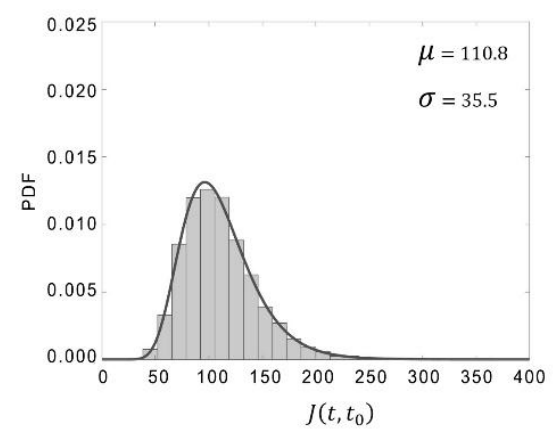

c)

Figure 8: Compliance - prior distribution for $\mathrm{t}=2297$ days: a) B3, b) EC2, c) GL2000. Estimated statistics and log-normal density fit also shown.

\section{Characterization of the posterior distribution for creep compliance}

Once the likelihood function (Figures 3 and 4) and the prior compliance distributions (Figures 7 and 8) have been obtained, the posterior compliance distribution was computed, by using either Single Point updating (SPO) or Sequential (SEQ) updating. The analytical formulation for obtaining the posterior distribution is presented in the Appendix, following the procedure presented in [13]. Figure 9 depicts the time profile of the mean compliance and its $\mathrm{CoV}$ for all three models, when performing SPO updating. Results for two different prediction dates, i.e. $t_{\mathrm{f}}=2297$ days which coincides with the last date for which measurements are available and $t_{f}=5840$ days which corresponds to about 10 years beyond that, are presented. Moreover, as previously mentioned, three measurement collection frequencies are considered, to investigate the effect of this factor on compliance statistics.

The main conclusion is that the $\mathrm{CoV}$ of the updated compliance distribution drops from a range of $29-37 \%$ (prior distributions) to $\cong 4.7 \%$. (posterior distributions), as a result of the influence of the much reduced and time invariant $\mathrm{CoV}$ associated with the likelihood. Indeed, it tends asymptotically to the latter as the period between the updating date and the final date becomes smaller. It is also worth noting that, in this case, the collection frequency makes practically no difference to the $\mathrm{CoV}$ profile of the updated compliance. 
With regard to the updated mean compliance, similar patterns are observed, regardless of the analytical model used or the value considered for $t_{f}$. In fact, for $t_{f}=2297$ days, the estimated compliance is practically the same ( $\cong 88 \mu \varepsilon / \mathrm{MPa}$ ) for all three models. The observed pattern with time could be explained by its experimentally observed counterpart, which also exhibits a similar fluctuation (see Figure 7).

In contrast, the updated value for the mean compliance at $t_{\mathrm{f}}=5840$ days shows somewhat different values depending on the model used (i.e. $97 \mu \varepsilon / \mathrm{MPa}$ for $\mathrm{B} 3,89 \mu \varepsilon / \mathrm{MPa}$ for $\mathrm{EC} 2$ and $96 \mu \varepsilon / \mathrm{MPa}$ for GL2000). For this case, the extrapolation made from $t_{f}=2297$ days to $t_{f}=5840$ days re-introduces, to some degree, the inherent differences that exist between the three selected models (see Figures 7 and 8). 


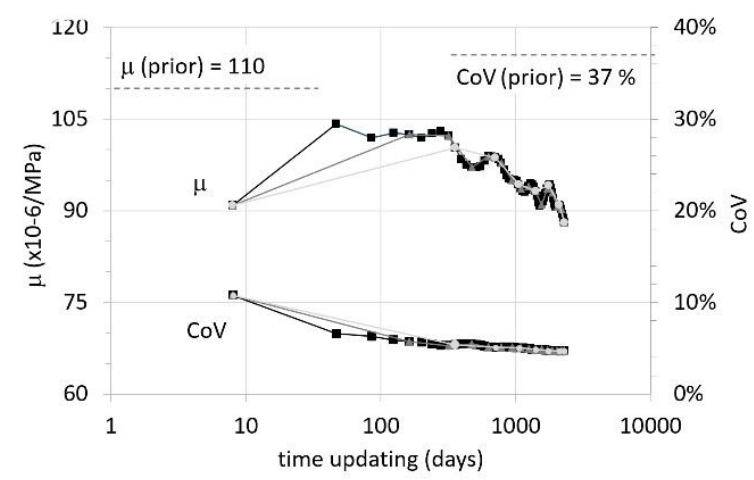

a)

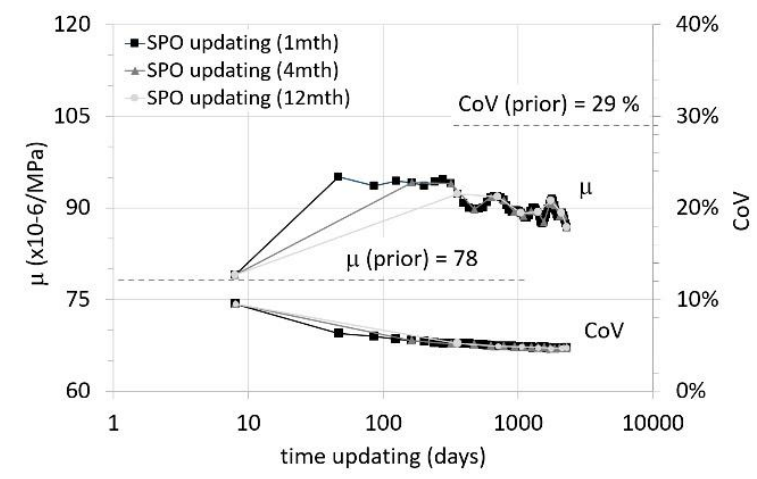

c)

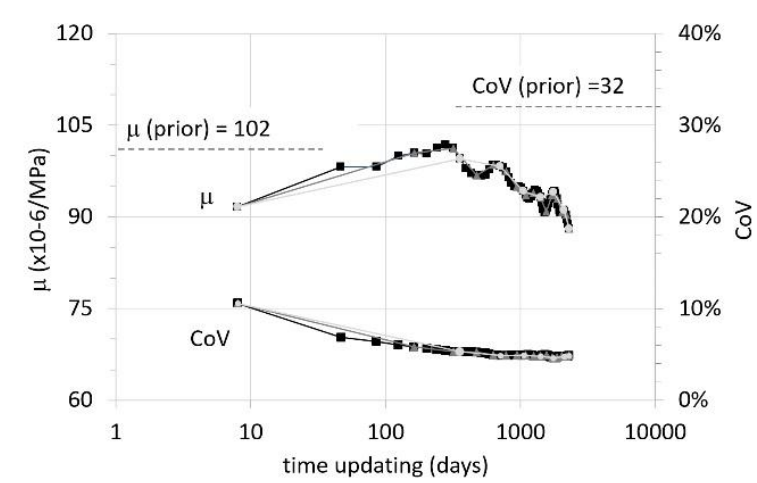

e)

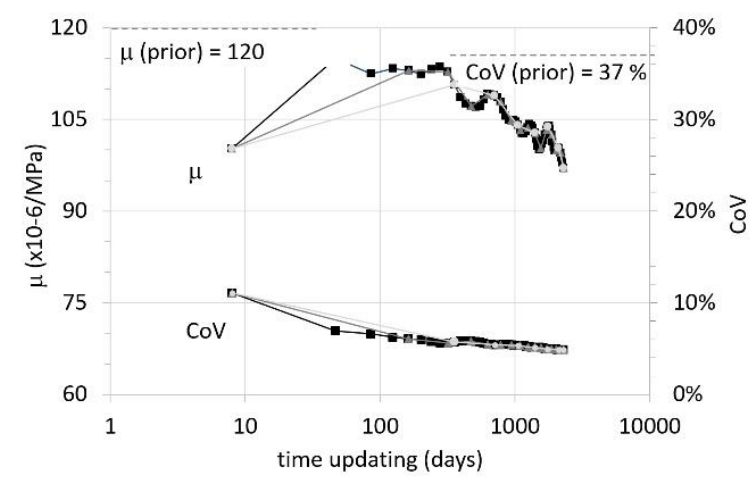

b)

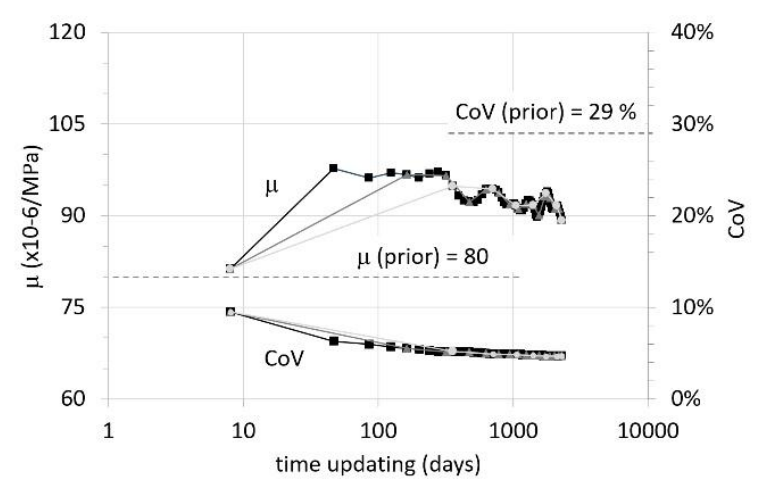

d)

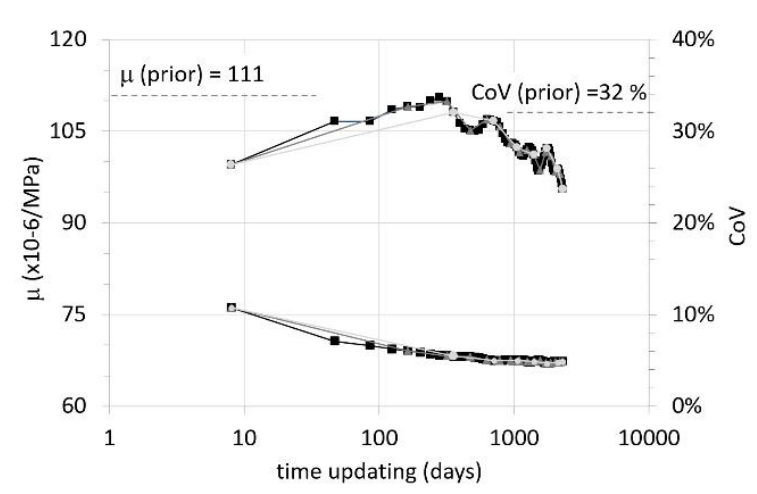

f)

Figure 9: SPO updating - mean, $\mu$, and $\mathrm{CoV}$ for the posterior distribution of compliance, $\left.J\left(t_{f}, t_{0}\right) \mid \tilde{J}\left(t_{i}, t_{0}\right): a\right) B 3$ for $t_{f}=2297$ days, b) B3 for $t_{f}=5840$ days c) EC2 for $t_{\mathrm{f}}=2297$ days, d) EC2 for $\mathrm{t}_{\mathrm{f}}=5840$ days, e) GL2000 for $\mathrm{t}_{\mathrm{f}}=2297$ days, f) GL2000 for $\mathrm{t}_{\mathrm{f}}=5840$ days.

Figure 9 shows the results for sequential updating (SEQ), following the same presentation format for predictions at $\mathrm{t}_{\mathrm{f}}=5840$ days only. The most striking observation is that the $\mathrm{CoV}$ of the updated compliance drops to a much lower value ( $\cong 1.4 \%$ ) for all three models. Moreover, the effect of the 
sampling rate (data collection frequency) is now evident, with the $\mathrm{CoV}$ dropping faster when higher collection rates are considered. Indeed, it is interesting to highlight that in order to get a CoV lower than $2 \%$ for the case of the EC2 model (Figure 10-a), it is necessary to monitor for 280 days if one measurement per month is collected, rising to 1100 days for one measurement per quarter and 2297 days for one measurement per annum. This also applies to the other two models (i.e. GL2000 and B3). It is also of interest to note the smooth profile of the updated mean compliance, when compared with respective results obtained with SPO updating (Figure 9-d), e) and f)). The updated mean compliances are also slightly higher, when compared to their SPO counterparts (e.g. from $97 \mu \varepsilon / \mathrm{MPa}$ to $104 \mu \varepsilon / \mathrm{MPa}$ for B3 model, from $89 \mu \varepsilon / \mathrm{MPa}$ to $93 \mu \varepsilon / \mathrm{MPa}$ for EC2 model and from $96 \mu \varepsilon / \mathrm{MPa}$ to $103 \mu \varepsilon / \mathrm{MPa}$ for GL2000 model). Indeed, in this case (SEQ updating) the updated mean compliance seems to be more dependent on the sampling rate. This might be explained by the memory that is encapsulated in the SEQ updating approach, which implies that subsequent updates depend on their predecessors (i.e. the posterior of the previous step becomes the prior of the following step). 


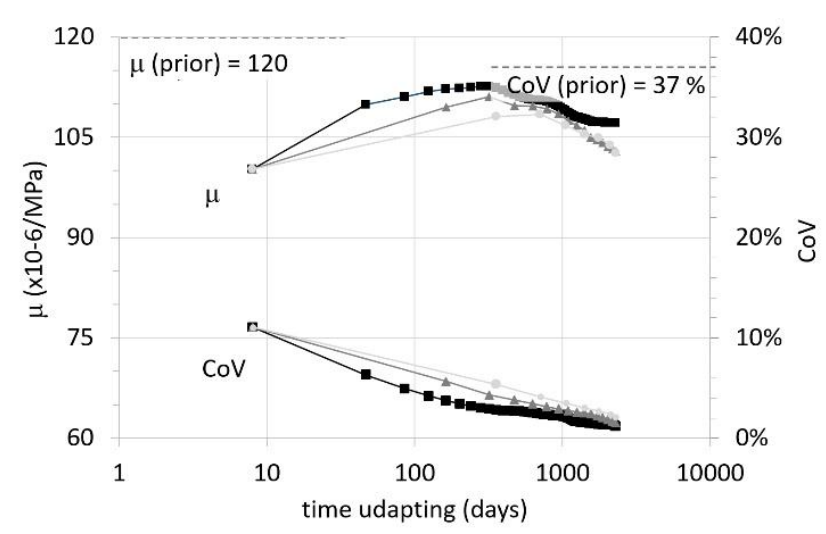

a)

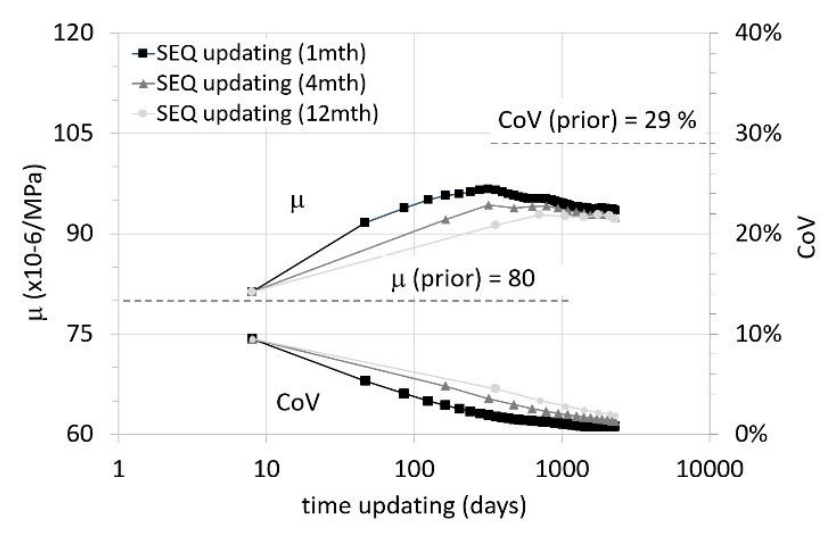

b)

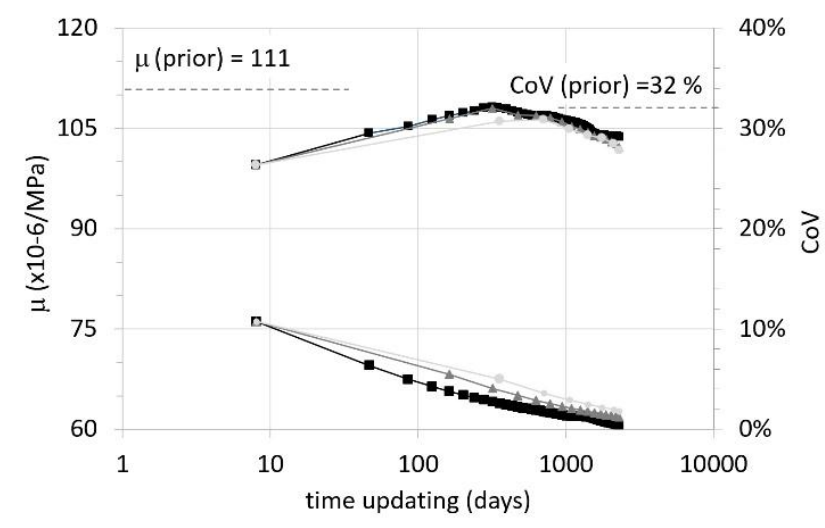

c)

Figure 10 SEQ updating - mean, $\mu$, and CoV for the posterior distribution of compliance, $\left.J\left(t_{f}, t_{0}\right) \mid \tilde{J}\left(t_{i}, t_{0}\right): a\right) B 3$ for $t=5840$ days, b) EC2 for $t=5840$ days, c) GL2000 for $\mathrm{t}=5840$ days.

With regard to monitoring requirements in a pre-posterior context, in Figure 10-a, the results obtained using sequential updating are re-cast with a view of quantifying the relationship between measurement collection frequency and the observation period required in order to reduce the $\mathrm{CoV}$ of 
the predicted compliance to an acceptable (or a target) value. As perhaps might be intuitively expected, the higher the collection frequency, the smaller the required observation period. In fact, the results indicate that the memory effect in sequential updating approach becomes increasingly powerful as the collection frequency increases. This is, of course, also dependent on the actual measurements, which in this case have provided a consistent trend (this would be one possible scenario in a pre-posterior analysis; an alternative might be to inject a level of inconsistency in the measurements with no clear mean value trend). Notwithstanding, considering the change in prediction variability against a combination of observation parameters, such as collection frequency and total period, seems to offer a sensible means of rationalising monitoring decisions in a value of information context. Based on the results presented in Figure 11-a, Figure 11-b shows how the trend could be extrapolated to 72 measurements collected per year (i.e. 6 measurements per month). It is evident that the required observation period decreases exponentially in relation to the total number of measurements collected per year. This means that the marginal benefit of collecting additional measurements per year decreases rapidly for values above 24 (i.e. 2 measurements per month).

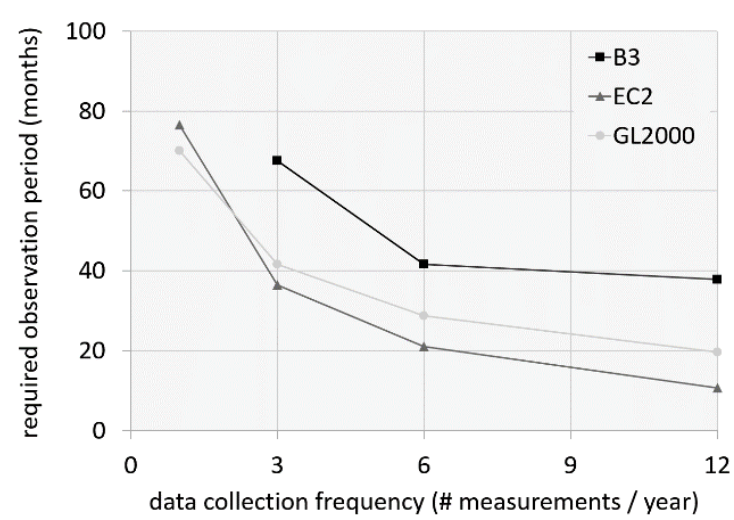

a)

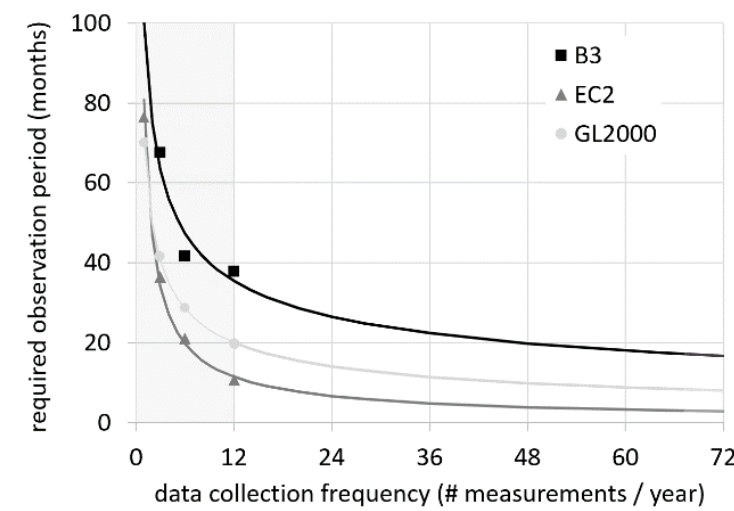

b)

Figure 11: Required observation period to obtain a CoV of $2 \%$ for $t_{\mathrm{f}}=5840$ days (SEQ updating): a) based on the available monitoring data, b) extrapolating for higher sampling rates. 


\section{Conclusions}

The objective of this paper was to investigate a Bayesian approach, which utilizes information from in-situ specimen creep data, for predicting creep compliance at different points in time during the service life of a bridge. Based on the presented results, the following conclusions can be drawn:

- It is evident that, even under relatively tightly controlled site-specific uncertainty modelling (as opposed to the wider uncertainty in considering a population of pre-stressed bridges), the prediction envelope for creep is quite wide. Generally, the CoV obtained for the predicted compliance for $t_{\mathrm{f}}=5840$ days is around $35 \%$.

- When using single point updating, the later the measurement is collected, the smaller is the uncertainty associated with the predicted compliance. At best, a CoV around $5 \%$ was achieved.

- When using sequential updating, the change in the CoV is highly dependent on the collection frequency: the more frequent is the collection, the lower is the computed CoV. At best, a CoV of approximately $1.5 \%$ was achieved.

- Comparing single point to sequential updating, it is evident that the latter is more powerful, though it also implies a higher monitoring cost since in-situ results would have to be collected more regularly. Making a choice between the two methods depends on the target $\mathrm{CoV}$ for predicted compliance, which is a function of both the structure's importance (in terms of failure consequences), the prediction date in comparison to the measurement dates, as well as the consistency revealed by the measurements vis-à-vis model predictions. All these factors can be addressed using the methodology presented in this paper.

- The specific conclusions regarding the quantitative reduction in the $\mathrm{CoV}$ of predicted creep compliance are a function of the particular measurements obtained in the case of this bridge. The values would clearly be different in a case where the trends were less consistent and/or the variance of the likelihood function was found to be substantially different. 
- The methodology could also be applied in a pre-posterior Bayesian context, where a designer of a creep-sensitive bridge might be interested in quantifying the required observation period (and hence the cost) in order to achieve a desirable target $\mathrm{CoV}$ for the predicted creep compliance at specimen level. In this case, a number of possible outcomes, in terms of the trend of experimental observations over time, would have to be considered within a decision analysis framework.

\section{Acknowledgements}

The first author acknowledges the support from the European Commission through the Marie Curie Grant Fellowship grant 660275 - LostPreCon under the program H2020-MSCA-IF-2014. The COST Action TU1402 on Quantifying the Value of Structural Health Monitoring has provided networking support. 


\section{Appendix}

Step 1: Identification and selection of the random parameters for the creep compliance

$X=\left[X_{1} . . ., X_{n} \ldots X_{N}\right], \mathrm{N}$ is the number of input random variables

Step 2: Probabilistic modelling of the random input variables

2.1. First and second order moments:

$\left(\bar{X}_{n} s^{X_{n}}\right), n=1,2, \ldots, N$

(Table 2)

2.2. Statistical dependence between random variables:

$\rho_{X_{i} X_{j}} i=1,2, \ldots, N \wedge j=1,2, \ldots, N$

(Table 3)

2.3. Selection of probability density functions (based on literature and site-specific information):

$f\left(\bar{X}_{n}, s^{X_{n}}\right), n=1,2 \ldots N$

(Table 2)

Step 3: Simulation sampling:

3.1. Generation of $\mathrm{K}$ random samples related to $\mathrm{N}$ standardized normal random variables (i.e. $\mu=0, \sigma=1$ ) and correlation matrix $\rho_{X_{i} X_{j}}$ :

3.2. Considering the mean and standard deviation of the $\mathrm{N}$ random variables $\left(\bar{X}_{n} \boldsymbol{s}^{X_{n}}\right)$, generation of K random samples for each variable by using the appropriate CDF (see Table 2). 
Step 4: Creep compliance time-profiles

Calculation of K creep compliance curves, as function on $\boldsymbol{X}$, for selected creep models, B3, EC2 and GL2000, respectively:

$\tilde{J}\left(t, t_{0}\right)=q_{1}+C_{0}\left(t, t_{0}\right)+C_{d}\left(t, t_{0}, t_{c}\right)$

$\tilde{J}\left(t, t_{0}\right)=\frac{1}{E_{c m, t o}}+\frac{\varphi\left(t, t_{0}\right)}{E_{c}}$

$\tilde{J}\left(t, t_{0}\right)=\frac{1}{E_{c m, t o}}+\frac{\emptyset_{28}\left(t, t_{0}\right)}{E_{c m 28}}$

(Figure 7.c)

Step 5: Prior distribution of creep compliance for time $t_{i}$

5.1. Estimation of the first and second order moments:

$\left(\overline{\boldsymbol{J}}, \boldsymbol{s}^{\boldsymbol{J}}\right), \overline{\boldsymbol{J}}=\left.\mu_{J}\left(t, t_{0}\right)\right|_{\boldsymbol{t}=\boldsymbol{t}_{\boldsymbol{i}}}$ and $\boldsymbol{s}^{\boldsymbol{J}}=\left.\sigma_{J}\left(t, t_{0}\right)\right|_{\boldsymbol{t}=\boldsymbol{t}_{i}}$

5.2. Specification of the prior distribution assumed to be lognormal:

$\left.\pi\left(J\left(t, t_{0}\right)\right)\right|_{t=t_{i}}=\frac{1}{s^{J} \cdot \sqrt{2 \pi} \cdot J} \exp \left[-\frac{1}{2}\left(\frac{\ln (J)-\bar{J}}{s^{J}}\right)^{2}\right]$

(Figure 8 for $\mathrm{t}=2297$ days)

5.3. Transformation to normal space through $Y=\ln (J)$

Step 6: Likelihood function for time $t_{i}$

6.1. Statistical processing of measurements: 
$\left.\overline{\tilde{\boldsymbol{J}}}, \boldsymbol{s}^{\tilde{\boldsymbol{J}}}\right), \overline{\tilde{\boldsymbol{J}}}=\left.\mu_{\tilde{J}}\left(t, t_{0}\right)\right|_{t=\boldsymbol{t}_{i}}$ and $\boldsymbol{s}^{\tilde{\boldsymbol{J}}}=\left.\sigma_{\tilde{J}}\left(t, t_{0}\right)\right|_{\boldsymbol{t}=\boldsymbol{t}_{\boldsymbol{i}}}$

(Figure 4)

6.2. Specification of the likelihood distribution, assumed to be lognormal, for all points in time where measurements are available $\left(0<t_{i}<t_{\text {final,observed }}\right)$ :

$\left.f\left(\left[\tilde{J}\left(t_{i}, t_{0}\right) \mid J\left(t_{i}, t_{0}\right)\right]\right)\right|_{t=t_{i}}=\frac{1}{s^{\tilde{J}} \cdot \sqrt{2 \pi} \cdot \tilde{J}} \exp \left[-\frac{1}{2}\left(\frac{\ln (\tilde{J})-\overline{\tilde{J}}}{s^{\tilde{J}}}\right)^{2}\right]$

6.3. Transformation to normal space through $\widetilde{Y}|\boldsymbol{Y}=\ln \tilde{\boldsymbol{J}}| \boldsymbol{l n} \boldsymbol{J}$

Step 7: Posterior distribution for time $t_{i}$

7.1. Estimation of the posterior distribution for $t_{i}\left(0<t_{i}<t_{\text {final,observed }}\right)$ using Bayes theorem and numerical integration in the transformed normal space:

$\left.\pi(Y \mid \widetilde{Y})\right|_{t=t_{i}}=c_{1} \times\left. f(\widetilde{Y} \mid Y)\right|_{t=t_{i}} \times\left.\pi(Y)\right|_{t=t_{i}}$

where $\boldsymbol{c}_{\mathbf{1}}=\frac{\boldsymbol{h}}{2 \boldsymbol{K}} \times \sum_{\boldsymbol{k}=\mathbf{1}}^{K}\left(\boldsymbol{g}\left(\boldsymbol{Y} \mid \widetilde{\boldsymbol{Y}}^{(k)}\right)+\boldsymbol{g}\left(\boldsymbol{Y} \mid \widetilde{\boldsymbol{Y}}^{(k+1)}\right)\right), \boldsymbol{g}=\boldsymbol{f}(\widetilde{\boldsymbol{Y}} \mid \boldsymbol{Y}) \times \boldsymbol{\pi}(\boldsymbol{Y})$

Step 8: Posterior distribution for time $t_{\text {final }}$ (extrapolated from $t_{i}$ )

8.1. Estimation of the mean and the standard deviation for $t=t_{\text {final }}$ ( where $t_{\text {final }}>t_{\text {final, observed }}$ ) in the transformed normal space:

$$
\left\{\begin{array}{l}
\left.\overline{Y \mid \widetilde{Y}}\right|_{t=t_{\text {final }}}=\left.\sum_{k=1}^{K} Y^{(k)}\right|_{t_{\text {final }}} \times\left.\pi\left(Y \mid \widetilde{Y}^{(k)}\right)\right|_{t_{i}} \\
\left.s^{Y \mid \widetilde{Y}}\right|_{t=t_{\text {final }}}=\left[\sum_{k=1}^{K}\left(\left.Y^{(k)}\right|_{t_{\text {final }}}-\left.\overline{Y \mid \widetilde{Y}}\right|_{t=t_{\text {final }}}\right)^{2} \times\left.\pi\left(Y \mid \widetilde{Y}^{(k)}\right)\right|_{t_{i}}\right]^{1 / 2}
\end{array}\right.
$$


8.2. Posterior distribution for $\mathrm{t}=\mathrm{t}_{\text {final }}$ in the transformed normal space:

$\left.f(Y \mid \widetilde{Y})\right|_{t=t_{\text {final }}}=\frac{1}{s^{Y^{\prime \prime}} \sqrt{2 \pi}} \exp \left[-\frac{1}{2}\left(\frac{Y-\overline{Y \prime \prime}}{s^{Y^{\prime \prime}}}\right)^{2}\right], \overline{Y^{\prime \prime}}=\left.\overline{Y \mid \widetilde{Y}}\right|_{t=t_{\text {final }}}$ and $s^{Y^{\prime \prime}}=\left.s^{Y \mid \widetilde{Y}}\right|_{t=t_{\text {final }}}$

8.3. Calculation of the posterior distribution in the original space $(J)$ and estimation of the first and second order moments:

$\boldsymbol{f}(\boldsymbol{J} \mid \tilde{J})$, where $\left.\boldsymbol{J}|\widetilde{J}|_{t=t_{\text {final }}}=\left.(\exp Y \mid \exp \widetilde{Y})\right|_{t=t_{\text {final }}}\right) \Rightarrow\left\{\begin{array}{l}\boldsymbol{\mu}=\left.\overline{\boldsymbol{J} \mid \tilde{J}}\right|_{t=t_{\text {final }}} \\ \boldsymbol{s}=\left.\boldsymbol{s}^{J \mid \tilde{J}}\right|_{t=t_{\text {final }}}\end{array}\right.$ (Figure 9 and 10) 


\section{References}

1. European Committee for Standardization (CEN), Design of concrete structures-Part 1-1:

General rules and rules for buildings, Eurocode 2: EN 1992-1-1. 2004, Brussels, Belgium: CEN.

2. Kristek, V., et al., Box girder deflections: Why is the initial trend deceptive? ACI Concrete International, 2006. 28(1): p. 55-63.

3. Bažant, Z.P., Q. Yu, and G.-H. Li, Excessive Long-Time Deflections of Prestressed Box Girders. I: Record-Span Bridge in Palau and Other Paradigms. Journal of Structural Engineering, 2012. 138(6): p. 676-686.

4. Wang, S. and C.C. Fu, Simplification of Creep and Shrinkage Analysis of Segmental Bridges. Journal of Bridge Engineering, 2015. 20(8).

5. Hubler, M.H., R. Wendner, and Z.P. Bažant, Comprehensive database for concrete creep and shrinkage: Analysis and recommendations for testing and recording. ACI Materials Journal, 2015. 112(4): p. 547-558.

6. Wendner, R., M.H. Hubler, and Z.P. Bažant, Statistical justification of model B4 for multidecade concrete creep using laboratory and bridge databases and comparisons to other models. Materials and Structures/Materiaux et Constructions, 2015. 48(4): p. 815-833.

7. ACI Committee 209, Guide for Modeling and Calculating Shrinkage and Creep in Hardened Concrete - ACI 209.2R-08. 2008, American Concrete Institute: Farmington Hills, USA

8. Bažant, Z.R. and G.H. Li, Unbiased statistical comparison of creep and shrinkage prediction models. ACI Materials Journal, 2008. 105(6): p. 610-621.

9. Han, B., et al., Sensitivity analysis of creep models considering correlation. Materials and Structures/Materiaux et Constructions, 2015: p. 1-11. 
10. Keitel, H. and A. Dimmig-Osburg, Uncertainty and sensitivity analysis of creep models for uncorrelated and correlated input parameters. Engineering Structures, 2010. 32(11): p. 3758-3767.

11. Madsen, H.O. and Z.P. Bazant, Uncertainty analysis of creep and shrinkage effects in concrete structures. Journal of the American Concrete Institute, 1983. 80(2): p. 116-127.

12. Bazant, Z. P. and J. C. Chern, Bayesian Statistical Prediction of Concrete Creep and Shrinkage. Journal Proceedings, 1984. 81(4): p. 319-330.

13. Bažant Z.P., Kim J.K., Segmental Box Girder: Deflection Probability and Bayesian Updating. Journal of Structural Engineering, 1989. 115(10): p. 2528-2547.

14. Goel, R., R. Kumar, and D.K. Paul, Comparative study of various creep and shrinkage prediction models for concrete. Journal of Materials in Civil Engineering, 2007. 19(3): p. 249-260.

15. TC-242-MDC RTC RILEM draft recommendation: TC-242-MDC multi-decade creep and shrinkage of concrete: material model and structural analysis*: Model B4 for creep, drying shrinkage and autogenous shrinkage of normal and high-strength concretes with multidecade applicability. Materials and Structures, 2015. 48(4): p. 753-770.

16. Gardner, N.J., Comparison of prediction provisions for drying shrinkage and creep of normal-strength concretes. Canadian Journal of Civil Engineering, 2004. 31(5): p. 767-775.

17. Bazant, Z. P., Creep and shrinkage prediction model for analysis and design of concrete structures-model B3. Materials and Structures, 1995. 28(6): p. 357-365.

18. Santos, L.O., Observation and analysis of the time dependent behaviour of concrete bridges. 2001, Univ. Técnica de Lisboa: Lisbon, Portugal 
19. Santos, L.O., Virtuoso, F., Fernandes, J.A., In situ measured creep and shrinkage of concrete bridges, $6^{\text {th }}$ International Conference on Creep, Shrinkage \& Durability Mechanics of Concrete and other Quasi-Brittle Materials - ConCreep 6, MIT, Cambridge, USA, 2001.

20. Li, C.Q. and R.E. Melchers, Reliability analysis of creep and shrinkage effects. Journal of Structural Engineering (United States), 1992. 118(9): p. 2323-2337.

21. Joint Committee on Strucural Safety,Probabilistic model code, available on http://www.jcss.byg.dtu.dk/Publications/Probabilistic_Model_Code [accessed 26/05/2018]

22. Diamantidis D, Madsen H, Rackwitz R. (1984) “On the variability of the creep coefficient of structural concrete.” Materials \& Construction 17(100): 321-8.

23. Fédération Internationale du Béton (fib) (2013). fib Model Code for Concrete Structures 2010. Lausanne, Switzerland

24. Bažant, Z. k. P., Q. Yu and G.-H. Li (2012). "Excessive Long-Time Deflections of Prestressed Box Girders. II: Numerical Analysis and Lessons Learned." Journal of Structural Engineering 138(6): 687-696.

25. Sousa, H., J. Bento and J. Figueiras (2014). "Assessment and Management of Concrete Bridges Supported by Monitoring Data-Based Finite-Element Modeling." Journal of Bridge Engineering 19(6): 05014002.

26. Hanselman, D., Mastering Matlab : a comprehensive tutorial and reference. 1996, Upper Saddle River. XII, 542 p.

27. Montgomery, D., Applied statistics and probability for engineers. 4 ed. 2007, New York. 